\title{
Teaching Distribution Planning: A Problem-based Learning Approach
}

\author{
Alex Grasas ${ }^{1}$, Helena Ramalhinho ${ }^{2}$ \\ (1) Department of Marketing, Operations and Supply \\ EADA Business School, Barcelona, Spain \\ agrasas@eada.edu \\ (2) Department of Economics and Business. \\ Business Analytics Research Group \\ Universitat Pompeu Fabra, Barcelona, Spain \\ helena.ramalhinho@upf.edu \\ Version: May 2014
}

\begin{abstract}
Purpose - The aim of this paper is to present a problem-based learning (PBL) activity that uses a decision support system (DSS) to teach one of the most fundamental topics in distribution planning: vehicle routing.

Design/methodology/approach - The authors describe their teaching experience in a Logistics and Supply Chain Management (LSCM) course. In the PBL activity proposed, students need to solve a typical vehicle routing case with no previous theoretical background taught. The paper is written as a teaching guide for other instructors, detailing how the activity may be carried out in class.
\end{abstract}

Findings - The PBL activity involved students from the very beginning, challenging them to solve a rather complicated problem. Its acceptance was very positive according to the students' feedback survey conducted after the activity. Only when struggling with the difficulties of the case proposed, students really appreciated the potential value of DSS to make better decisions. Moreover, this activity raised concern about how DSS must be adapted for implementation in every particular business scenario.

Originality/value - Teaching Logistics Management goes beyond lecturing on elemental concepts and tools, it is also about applying this knowledge to manage things. Although several PBL initiatives have been reported successful in the field of LSCM, this one incorporates a web-based DSS. The main issue in PBL activities is finding authentic and representative problems to develop transferable skills, and nowadays most logistics problems are solved using DSS.

Keywords: Problem-based Learning, Decision Support System, Teaching, Vehicle Routing Problem, Logistics Management

Article Classification: Research paper 


\section{Introduction}

Distribution planning is a key topic in Logistics and Supply Chain Management (LSCM) as it determines how and when goods are going to arrive in the customer's hands. Since goods are rarely produced and consumed at the same place, basically everything must be distributed. Distribution is then a significant component of the final cost of the goods, generally from $10 \%$ to $20 \%$ (Toth and Vigo, 2002). Environmentally, the distribution impact is also considerable. In Europe, for instance, it is responsible for about a quarter of the EU's greenhouse gas emissions (European Comission, 2011). Therefore, careful distribution planning can save significant operational costs while making the company more eco-friendly.

Distribution planning problems are complex and involve multiple variables, so the use of decision support systems (DSS) is essential to make better decisions (Chou et al., 2004). Since the number of companies that rely on these computerized systems is growing in all industries (Sweeney et al., 2010), it is important to give some exposure in LSCM courses. In a comprehensive study of contemporary logistics education, (Wu, 2007) declares that "efficient logistics and smooth supply chain management will not be possible without sufficient IT support”. The integration between Information Technology and Logistics is indispensable for future logisticians. Eventually, LSCM students will certainly have to deal with DSS in their careers. A DSS comprises, behind its interface, sophisticated algorithms, databases, etc., which may be familiar for engineers or computer scientists, but may be unknown for users from other disciplines. Introducing DSS in LSCM syllabi is a way of breaking with the black-box perception by these technically unsophisticated users. When it comes to technical aspects, teaching in management courses becomes a challenging task due to the probable heterogeneity of the students with regards to their mathematical and programming backgrounds. Although they do not need to learn how to develop a DSS, they should be familiar with and aware of the potential of these applications (Ben-Zvi, 2007). Only then will they appreciate the difficulties that may arise in the DSS design and implementation. To better introduce technical content in a LSCM course, the instructor should engage students in class, and this can be achieved by original and less conventional teaching methods like the one presented in this paper.

In particular, a problem-based learning (PBL) activity supported by a DSS is proposed to teach vehicle routing, one of the most fundamental topics in distribution planning. PBL is an active learning strategy that uses realistic and ill-structured problems to trigger learning. Students, grouped in teams, have the control of the learning process: they need to analyze the problem, decide what knowledge is needed, gather relevant data, and find corresponding solutions (Smith, 2005). PBL has its origins at McMaster Medical School in the late 1960s, and has since been adopted by schools in many fields (e.g., engineering, architecture, law, management). In LSCM, active learning initiatives like games or simulations are commonly used (Gravier and Farris, 2008), and some successful PBL activities have been reported (Alvarstein and Johannesen, 2001). One of the main issues in PBL approaches is finding authentic and representative problems to develop transferable skills. Since nowadays logistics problems are mostly solved using DSS, the PBL activity proposed in this paper incorporates a web-based application to support the decision making. The objective of the activity is threefold: (1) to teach the best known and commonly used algorithm in vehicle routing, the Clarke and Wright savings heuristic (Clarke and Wright, 1964); (2) to develop/enhance soft skills like cooperative learning, data gathering, critical thinking, team work and communication skills; and

(3) to create awareness among students on the importance of DSS for solving complex real-life situations.

The remainder of this paper is structured as follows. Section 2 reviews active learning methodologies in the context of LSCM. Section 3 describes the PBL activity designed to teach 
vehicle routing using a DSS in a LSCM course. Section 4 discusses insights and lessons learned throughout the process. Finally, Section 5 provides conclusions and future directions.

\section{Active Learning in Logistics and Supply Chain Management}

Active learning refers to instructional strategies that actively engage students in the classroom (Mabrouk, 2007), where traditional lectures are substituted by experiential-learning activities supervised by the instructor. This student-centered methodology contributes positively to the teaching process, independently of the discipline taught (Hmelo-Silver, 2004). Educators agree on the fact that students do not follow the same learning style and this may lead to inequalities among students in their learning process (Chwif and Barretto, 2003). Active learning copes with that by integrating different students in a more relaxed and fun environment while reinforcing the concepts taught in theoretical classes (McKone and Bozewicz, 2003).

One of the criticisms to logistics education, according to (van Hoek, 2001), is the "lack of practical and professional skills development". The author urges the presence of interactive lectures to support this development. An applied discipline like LSCM is within the myriad of areas in which active learning provides excellent teaching opportunities, especially when there exists a lack of interest from its students (Lancioni et al., 2001). In addition, in LSCM courses intended for management programs, participants may have limited quantitative skills, knowing nothing about most Operations Research techniques frequently used in Logistics. Since this difficulty may discourage students, logistics educators should favor the use of interactive methods to boost their interest for the subject, and to enhance their analytic and intuitive abilities (Gammelgaard and Larson, 2001).

Many activities fall under the umbrella of active learning like, for example, cooperative/collaborative learning, case studies, games and simulations. In the field of Logistics and Supply Chain, one of the most popular active learning activities is the Beer Game simulation (Sterman, 1989). The game was designed to understand the dynamics of a supply chain and the bullwhip effect, and there have been numerous variants since its development in the 1960's (Jacobs, 2000). There exist many other forms of active learning in the literature. (Johnson and Pyke, 2000) examine activities used in supply chain management courses in engineering and business schools. (Lewis and Maylor, 2007) analyze the contents and processes of more than two-hundred logistics and other operations management-related games. (Wood, 2007) focuses on online games, classifying the most relevant. (Jahangirian et al., 2010) review almost 300 simulation applications within manufacturing and business.

The focus of this paper is on another type of active learning known as problem-based learning. PBL is considered a subset of cooperative/collaborative learning (Thomchick, 1997), where students are grouped to learn specific topics by tackling open-ended and ill-defined problems (Mabrouk, 2007). The use of PBL helps students to experience realistic cases and not just theoretical scenarios, forcing them to define the problem and make proper decisions to find a solution. PBL activities are common in the broader area of Operations Management (OM). For example, (Kanet and Barut, 2003) describe their PBL experience in an MBA production management course. They also analyze the effectiveness and appropriateness of this approach in business education. (Hung et al., 2003) expose a PBL project for engineering students that simulates a real manufacturing problem. (Léger et al., 2012) present a problem-solving experience within an enterprise resource planning (ERP) system. Students operate a near reallife company using a simulator that connects to the full ERP system (SAP). Also in the context of OM education, (Bamford et al., 2012) point out one of the main drawbacks in using PBL 
approaches: the grade assessment. Based on their PBL experience, they claim that although PBL improves learning, it makes student assessment more difficult.

Restraining the review to the use of PBL resources in LSCM, (Alvarstein and Johannesen, 2001) design an entire logistics and transportation course using this methodology. They partition the contents of a regular course into six problem areas, each of which is approached using a PBL activity. A similar method is followed by (Carravilla and Oliveira, 2004) in a logistics course of a computer and electrical engineering degree. (Gudmundsson and Nijhuis, 2001) propose a master's course that combines case teaching and PBL with a novel evaluation procedure carried out by the students divided into three groups: problem-solvers, decisionmakers and evaluators. (Kanet and Stößlein, 2008) integrate PBL in a web-based supply chain game. The game represents almost half of the SCM course and includes decisions on forecasting, facility location, transportation, and inventory management. (Ahern, 2010) describes two PBL-based case studies in a transportation course of a civil engineering degree, the first on transportation policies, and the second on transportation modeling. None of the PBL approaches reviewed deals with a VRP as this paper does. Only (Campbell et al., 2000) include a routing problem in their teaching experiences reported in supply chain, but students solve it using commercial software after being lectured on routing and scheduling.

A fundamental aspect for a successful PBL application is the problem selection. This problem should be interesting, realistic and moderately challenging (Hmelo-Silver, 2004). On one side, problems that can be solved straightforwardly can create indifference. On the other side, complicated problems can be overwhelming, making learners unmotivated to invest time in developing a solution. Finding a right balance for an appropriate educational problem in the context of VRP is not easy. Real problems of this type are nowadays solved using decision making software. (Campbell et al., 2000) and (Sweeney et al., 2010) corroborate this and contribute to the LSCM teaching literature by developing courses that use commercial LSCM software. Students can then realize the value and the role of this software in real-life decision making. To the best of our knowledge, few PBL activities in the context of OM and LSCM explicitly incorporate information technology tools. (Léger et al., 2012)'s ERP simulation is a happy exception of that. The PBL activity in the present paper includes a companion DSS to better understand the problem posed and to make students aware of the importance of such tools in reality. Although the web-based application has been developed for teaching purposes, it adds a realistic touch to the activity.

\section{The PBL approach: activity description}

\subsection{Context and theoretical background}

The PBL activity presented in this paper has been used as part of the Distribution Planning module of a course called "Business Logistics". The course, which covers LSCM topics, is an undergraduate course offered in the third or fourth year of the Bachelor's degrees in Business Management and Administration, in Business Sciences, and in International Business Economics. The course is usually taken after an introductory OM course, and has a duration of thirty lecture hours (three hours weekly), and nine seminar hours in one quarter. Given the topics covered in the activity, though, it could be also used in an Operations Management, or Quantitative Methods course, at both undergraduate and graduate levels (e.g., MBA). In fact, a preliminary version of the current activity was implemented by one of the authors in the "Management Science and Business Information Systems" course of a Master of Science in Information and Communication Technologies Strategic Management (Grasas et al., 2013). That first experience was useful to fine tune some details of the current PBL activity. 
The Distribution Planning module includes one of the most relevant problems in distribution faced by many companies in numerous industries, the vehicle routing problem (VRP). All tangible products, from raw materials to components and finished goods, must be distributed to factories, warehouses, stores, or customers' homes. Companies then need to design routes to deliver all these products. In a VRP, in particular, a set of geographically dispersed customers with known demands has to be serviced by a set of capacitated vehicles departing from and finishing at a depot. The objective is to find a set of delivery routes that satisfies all operational constraints and minimizes total transportation costs. This problem has been studied for over 50 years, and there exist multiple variants that adapt the problem to the very different operational constraints and specifications found in reality (Toth and Vigo, 2002) (Laporte, 2009). Variants of the problem include time windows to visit customers, pickup and delivery at the customer, heterogeneous vehicles, multiple depots, stochastic demands, etc.

Solving a VRP optimally, even in its simplest version, is very complex as the problem size increases. Since exact methods can handle up to 50 or 75 customers only, one must resort to heuristic approaches for relatively large problems. A heuristic is a computational method tailored to solve large optimization problems, like the VRP, known to be very complicated to solve optimally. A heuristic starts from an initial solution and searches iteratively for better solutions using a series of rules and conditions. Heuristics are usually simple, easy to implement, robust and highly effective on difficult problems. One of the most fundamental and commonly used heuristics for solving the VRP is the Clarke and Wright savings (CWS) heuristic. This is a rather intuitive method that starts by assigning one vehicle to each customer. Given a distance matrix with all distances (or costs) between every pair of locations, a savings matrix is calculated. The savings matrix represents the savings obtained by consolidating two customers on a single vehicle. At each iteration, the algorithm takes the pair of customers with the greatest savings and joins the two routes as long as the new merged route is feasible (i.e., it satisfies the vehicle capacity constraint). The merging procedure continues until no more routes can be merged. Finally, after all routes have been obtained, the algorithm identifies the sequence in which each vehicle will visit customers. There exist many more heuristics that build on this savings heuristic to enhance its performance or to solve variations of the standard VRP.

\subsection{The DSS tool developed}

Due to the complexity of VRP problems in real life, many companies (large companies especially) use some kind of software or DSS tool to help the decision making. See, for example, real applications in the literature by (Ruiz et al., 2004), (Faulin et al., 2005) or (Andrade-Pineda et al., 2013). The PBL activity proposed is supported by an open web-based tool specifically created for this project. Figure 1 shows a screenshot of the home page, which can be found at http://vrp.upf.edu/. The tool has been developed for educational purposes only and the website is open to everyone. This educational DSS is aimed to help students understand and solve the VRP. The main application is based on the CWS algorithm and integrated with Google Maps to improve its presentation, realism and usability. The website has six sections:

(1) CWS algorithm. This is the main section, where the user enters a text file with all inputs (addresses, demands, truck capacity), and the software returns the CWS solution with all routes plotted on a Google map.

(2) CWS algorithm with manual inputs. This part solves the problem as before but the user needs to enter all data manually one by one.

(3) User manual and templates. A user manual and the different sample files can be downloaded in this section. 
(4) Distance matrix. This section calculates a distance matrix after uploading a text file with all postal addresses.

(5) Solution checking. This part is intended for instructors to check the feasibility and cost of the solutions proposed by the students.

(6) Step-by-step CWS. This section allows solving the VRP step by step using the CWS algorithm. The user must enter manually all inputs, calculate the distance and savings matrices and decide the routes. The software checks whether all steps performed are correct.

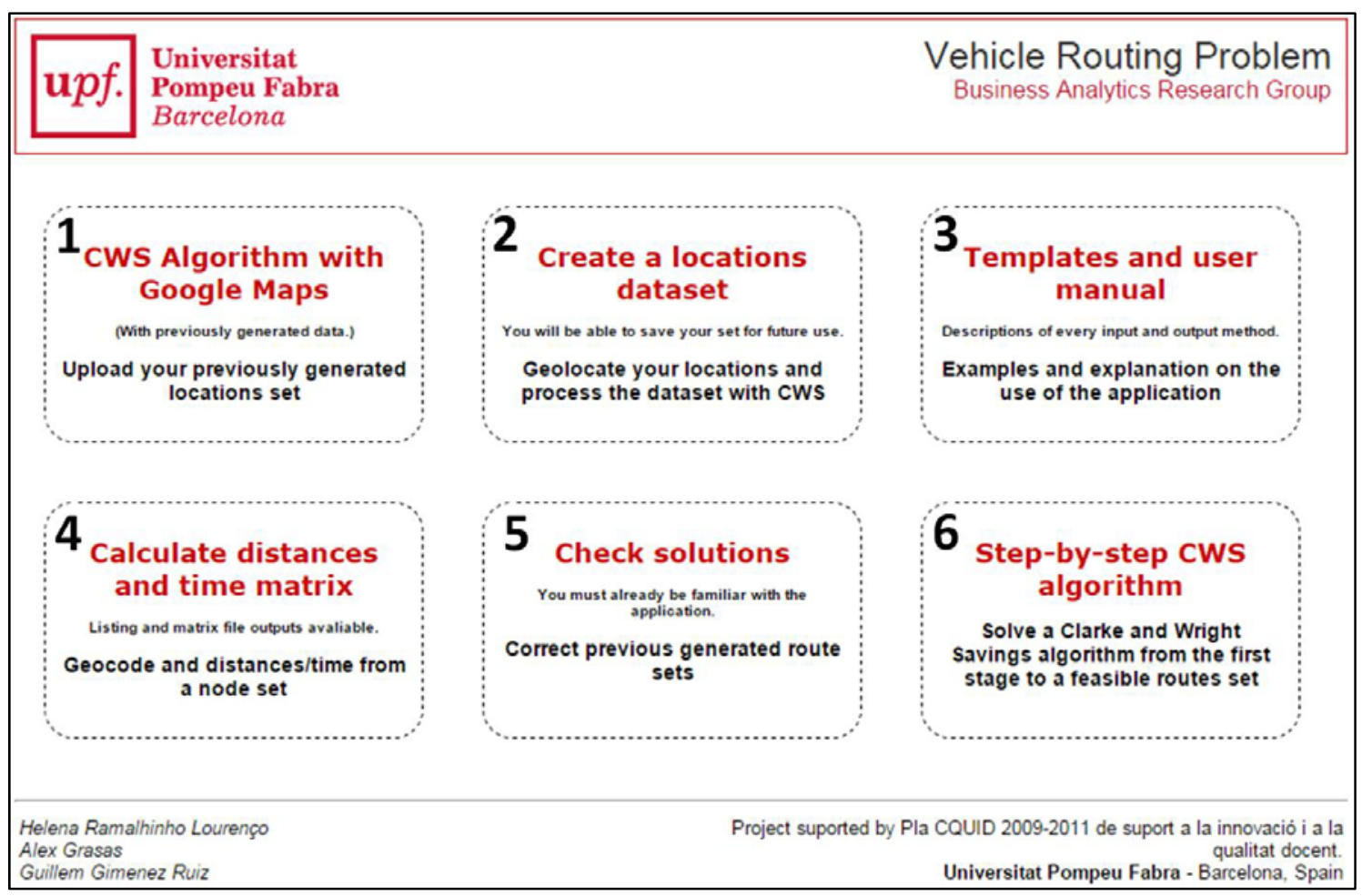

Figure 1. Screenshot of the DSS home page (http://vrp.upf.edu/)

\subsection{Teaching Plan}

The Distribution Planning chapter in the "Business Logistics" course starts with the PBL activity, and it is carried out over two or three consecutive lectures, on different days. It is recommendable to allow at least one week between the first two lectures so that students can work on the problem assigned. In the first lecture, there is a brief discussion on distribution in general, and routing problems, in particular, highlighting their importance for companies. At this point, no solution methods for the VRP have been introduced yet. Students are then divided into groups of four or five people, and given a problem to solve.

This problem involves a fictitious company that needs to distribute its products to a network of twenty stores located in different shopping malls in a city's metropolitan area (Barcelona metropolitan area). The use of a local example is recommended to motivate students; they become more familiar and better appreciate the relevance of the problem. A 20-customer VRP is a reasonably sized problem considering that students will most likely solve it manually. It is neither too small to find an optimal solution easily nor too complicated to find a near optimal solution. The exercise contains the postal addresses of each mall, the demand for each store, and the capacity of the available trucks. This exercise can be found at the end of the user's manual posted on the website. The goal of the exercise is to design the routes to deliver the products to 
all stores trying to minimize the total cost and without violating the truck-capacity constraints. The cost function is assumed to be proportional to the distance traveled by all vehicles. To simplify things, fixed costs of using a vehicle are disregarded so students can focus strictly on minimizing distances. Teams will be competing to each other to see which group can find the best results. Competition is a common desired feature in simulation games. It creates an additional pressure that may resemble a real competitive business scenario (Lewis and Maylor, 2007) and increases the motivation for the activity (see results from the students' survey in Section 4).

In the second lecture, teams must provide their proposed solution containing the routes to all stores as well as the total distribution cost (i.e., distance). During the week between lectures, the DSS tool is disabled so that students cannot use the algorithm to compute their solutions. They are allowed, however, to use any other source or look up elsewhere. This second class starts with a brief exposition by some groups, describing their solution and how they reached it. Different groups are asked and their solutions compared. The first obstacle encountered is in the data gathering. It is now a suitable moment to center the discussion on the relevance of data. Some questions that can be raised: "How to obtain appropriate data to solve the problem?", "What are the costs/difficulties of obtaining this data?", "What if there were 200 customers instead of 20, would it be as difficult?” For instance, most groups opt not to search for distances among all stores because it is quite tedious and cumbersome (even with only 20 stores). For that reason, they mostly use a graphical approach to solve the problem. That is, they locate the stores on a map, and group them by proximity. The exercise, however, is fine-tuned so that close stores have total demand larger than the vehicle capacity. Some students have previously taken an introductory Operations Research course, and learned Linear and Integer Programming. They soon discard this option after observing the difficulty of the problem formulation. Another possibility often used is a trial-and-error approach. Overall, it is not rare to have groups unable to find a feasible solution; some common errors are violating the capacity constraint of a vehicle, or even forgetting a customer. No team has ever tried to use a DSS or any kind of algorithmic solution. At most, some of them prepare basic Excel spreadsheets to perform some calculations, but that cannot be even considered a form of DSS.

Next, the best solutions are checked in front of the class using Section 5 of the VRP website. After that, the instructor explains and formulates the VRP. Students now know the complexity of the problem and of finding reasonable solutions. To cope with that, the instructor introduces heuristic methods, which can find relatively good solutions in little time. The CWS heuristic is described and employed to solve an example with 8 customers. Once the different steps of the algorithm are clear, the initial problem is solved with the web application again.

The methodological part of the exercise concludes here, and now the discussion acquires a more managerial tone. This may be left for a third lecture depending on the time spent. Students recognize the need for finding some tool to approach this type of problems as they can imagine the difficulty of solving a real problem instance -e.g., a company having to distribute goods to hundreds of stores. This opens an opportunity to mention that companies use software for distribution planning that ranges from strategic tools for network design to more operational optimization packages for inventory management or vehicle routing. Then, the web-based tool developed for the exercise is explained. Students are quite amazed by how a solution (usually better than theirs) is just a couple of clicks away. They are also quite intrigued by the use of other DSS in logistics decisions. On the other side, there are critics and skeptics too, who look for issues and dysfunctions of the system. This provides a perfect scenario to discuss the use of DSS: advantages, limitations, threats, etc. It is important to remark that they are not the panacea to solve all problems, they need to be adapted to every business context and companies' 
requirements, but they can be a good supporting tool. In the end, decisions must be made by people not machines.

\subsection{Deliverables and assessment}

Each team needs to submit a report at the beginning of the second session explaining all work done in detail. This report must include the following parts:

- Outline of the problem approach: brief summary of the steps followed to tackle the problem.

- Challenges and problems encountered: explanation of all obstacles found in the resolution of the problem.

- Set of routes to all stores: number of vehicles (routes) needed and the delivery sequence.

- Total cost of the solution: sum of all distances traveled by all vehicles.

- Methodology: description of the methodology used to come up with the solution.

- Real implementation: open discussion on how companies should solve these problems and implement their solutions.

- Sources: list of books, papers, websites, and other references looked up to solve the problem.

Additionally, for small class sizes and time permitting, different groups can also expose orally the points listed above in front of their classmates. This gives students an opportunity to practice their presentation skills too. In the course, this activity is worth $10 \%$ of the final grade. The remainder grade comes from a final exam and seminar exercises/cases turned in throughout the course. The grades obtained in this exercise are usually high, as students, motivated by the challenge, spend considerable time in the resolution.

\section{Results and insights}

Several studies show the advantages of PBL approaches in terms of cognitive and behavioral outcomes (Brownell and Jameson, 2004). Cognitively, students gain factual knowledge by searching for resources, and using them to solve similar problems in the future. Behaviorally, PBL makes students collaborate to identify, define, and solve business cases, applying analytical methods when necessary. Also from a behavioral perspective, during team discussions they interact with others and may need to influence or convince them. The presentation of results in the second part of the activity can also include a formal exposition which helps developing their communication skills too.

Educators believe that PBL increases learning compared to conventional exams, and encourages further studying. The PBL activity in the logistics course replaced a quiz on distribution planning one year ago, and has been used ever since. The better results in the grades seem to confirm this impression, with some caveats though: the student sample may not be representative, and the two scenarios, before and after the PBL implementation, may be too different to extract a definite conclusion. Grades aside, the activity has generally had a very good acceptance among students in all courses where it has been used. Students fill up a quick survey to evaluate the activity and the lessons learned. The survey was developed using an online tool and emailed to all students that participated in the activity (two groups of 70 students). This preserves respondents' anonymity which diminishes a potential bias in the results. Table 1 contains the 20 questions asked with the corresponding responses (a total of 66). The questionnaire was divided into three parts: 
- Background: this part asks for previous knowledge on the topics related with the PBL activity (e.g., VRP, DSS).

- Activity: this part enquires about the PBL activity itself in terms of difficulty, motivation, time spent, methodology, etc.

- Conclusions: this part tries to capture the learning achievement obtained by the students after the PBL activity.

\begin{tabular}{|c|c|c|c|c|c|c|c|}
\hline & $\begin{array}{c}\text { Very Low } \\
1 \\
\end{array}$ & $\begin{array}{c}\text { Low } \\
2 \\
\end{array}$ & $\begin{array}{c}\text { Average } \\
3 \\
\end{array}$ & $\begin{array}{c}\text { High } \\
4 \\
\end{array}$ & $\begin{array}{l}\text { Very High } \\
5 \\
\end{array}$ & Mean & SD \\
\hline \multicolumn{8}{|l|}{ Background Knowledge of ... } \\
\hline 1. VRP & $41 \%$ & $23 \%$ & $24 \%$ & $6 \%$ & $6 \%$ & 2.14 & 1.20 \\
\hline 2. Operations Research & $20 \%$ & $30 \%$ & $29 \%$ & $21 \%$ & $0 \%$ & 2.52 & 1.04 \\
\hline 3. Heuristics & $35 \%$ & $27 \%$ & $18 \%$ & $15 \%$ & $5 \%$ & 2.27 & 1.22 \\
\hline 4. DSS & $40 \%$ & $46 \%$ & $11 \%$ & $3 \%$ & $0 \%$ & 1.77 & 0.77 \\
\hline 5. Quantitative Methods & $6 \%$ & $30 \%$ & $47 \%$ & $17 \%$ & $0 \%$ & 2.74 & 0.81 \\
\hline \multicolumn{8}{|l|}{ VRP Activity } \\
\hline 6. What was the difficulty of the activity? & $0 \%$ & $5 \%$ & $65 \%$ & $25 \%$ & $5 \%$ & 3.30 & 0.64 \\
\hline 7. Did the activity motivate you? & $0 \%$ & $5 \%$ & $17 \%$ & $51 \%$ & $27 \%$ & 4.00 & 0.80 \\
\hline 8. Did you obtain a feasible solution? & $2 \%$ & $6 \%$ & $27 \%$ & $48 \%$ & $17 \%$ & 3.73 & 0.88 \\
\hline 9. Did you look up additional material to solve it? & $21 \%$ & $24 \%$ & $30 \%$ & $17 \%$ & $8 \%$ & 2.68 & 1.22 \\
\hline 10. Is the time spent on the activity adequate? & $3 \%$ & $13 \%$ & $56 \%$ & $21 \%$ & $8 \%$ & 3.17 & 0.87 \\
\hline 11. Did the activity stimulate teamwork? & $4 \%$ & $4 \%$ & $27 \%$ & $41 \%$ & $25 \%$ & 3.80 & 0.98 \\
\hline 12. Was workload balanced among team members? & $4 \%$ & $5 \%$ & $26 \%$ & $39 \%$ & $26 \%$ & 3.79 & 1.01 \\
\hline $\begin{array}{l}\text { 13. Did competition against other groups increase } \\
\text { motivation? }\end{array}$ & $2 \%$ & $7 \%$ & $19 \%$ & $39 \%$ & $33 \%$ & 3.95 & 0.99 \\
\hline $\begin{array}{l}\text { 14. Do you think collaborative learning approaches like } \\
\text { this help to better understand/learn from the problem? }\end{array}$ & $0 \%$ & $0 \%$ & $5 \%$ & $35 \%$ & $60 \%$ & 4.54 & 0.60 \\
\hline \multicolumn{8}{|l|}{ Conclusions } \\
\hline 15. What is your knowledge of the VRP? & $0 \%$ & $9 \%$ & $46 \%$ & $40 \%$ & $5 \%$ & 3.42 & 0.73 \\
\hline 16. What is the relevance of the VRP in real life? & $0 \%$ & $0 \%$ & $7 \%$ & $42 \%$ & $51 \%$ & 4.44 & 0.63 \\
\hline 17. What is your knowledge of the CWS algorithm? & $12 \%$ & $16 \%$ & $30 \%$ & $28 \%$ & $14 \%$ & 3.16 & 1.22 \\
\hline
\end{tabular}

Table 1. Student survey to evaluate the PBL activity

The results from the Background part are quite revealing. The low score on these questions (Questions 1-5) is a clear indicator for management instructors to promote the use of analytical methods and software tools in class. This will better prepare students for real-world logisticsand supply chain-related problems that they may face in their companies in the future.

The answers in the Activity part are satisfactory in general. Students seem quite motivated with the activity (Question 7), a motivation surely strengthened by the competition component (Question 13). As mentioned in Section 2, problem choice is very important in PBL: one needs to calibrate the problem difficulty, and find the appropriate context. Choosing a local example, in this case a set of nearby shopping malls that are familiar to the students adds realism and is perceived as if the problem was specially designed for them (rather than excerpted from any book). The VRP exercise used seems well-designed in this sense as its difficulty is normal (Question 6), most groups could obtain feasible solutions (Question 8), and time spent by the students seems adequate (Question 10). This perceived difficulty may explain the low need for extra resources to solve the problem (Question 9). As explained in Section 3.4, this activity has a single grade per team. Although the activity stimulates teamwork (Question 11), one of the criticisms of group work assessment is ensuring fairness among students due to the difficulty of attributing individual grades from a single summed-up output (Bamford et al., 2012). In this case, students were asked to evaluate the relative contribution of each member of the group. The work load distribution was quite uniform in all groups (Question 12). 
The (only) drawback observed from the survey regards the theoretical knowledge acquired by the students. The grades on Question 15 are reasonable: after this activity, students are not expected to become experts on VRP as this is a very broad problem with countless variants and peculiarities. Results on Question 17 are more questionable though. The methodological part of the CWS algorithm could be reinforced. This is an extension planned to be implemented in future courses. More details are given in the Conclusions section.

Finally, Question 14 yields very rewarding results from a pedagogical standpoint, and justifies the use of this active learning tool. A great majority rates the PBL approach very useful to understand the problem and its resolution. Students are generally very satisfied with the experience (Question 19) and would recommend it for other courses (Question 20). Some other benefits reported informally include improvements on: problem analysis, distinction of relevant data, and problem solving skills. They all realize of the relevance and difficulty of routing decisions in real life (Question 16), and that some type of technological support is crucial to make better and more efficient decisions (Question 18). They also appreciate the (usually first) exposure to DSS tools and having discussed their advantages and limitations. As future managers, they are going to be developers and consumers of these computerized tools.

\section{Conclusions}

Teaching LSCM in management programs poses singular challenges, as business students have traditionally shown indifference toward this subject due to lack of knowledge, limited exposure, or quantitative subject aversion. As an applied discipline, LSCM education must be addressed from both theoretical and practical standpoints. LSCM teaching methods need not only to help the concepts to be learned, but also to allow this knowledge to be applied in real-life situations. And the latter cannot be achieved by conventional instructor-centered lectures but by active learning approaches like the one presented in this paper. In particular, a PBL activity was proposed to study a fundamental problem in distribution planning, the VRP. This activity was complemented with a web-based DSS tool to better understand the solution method and to show students the need for decision making software in complex problems: a necessity that has been growing due to the sophistication of logistics problems as well as the ever-increasing data availability (Big Data phenomenon).

Management students will have to deal with business problems in their careers. Problemcentered approaches like this one narrow the gap between theory and practice. Placing students in a situation that could be faced by a real company, and challenging them to resolve it is an excellent way to motivate the activity. Competition also plays a key role intensifying this motivation. With the struggle to solve a VRP, some students even recognize for the first time the necessity and implied costs of shipping products to stores. Having products available on the shelves when shopping is something that they may take for granted and have never wondered about. In general, such hands-on experiences work really well in class, as can be seen from the students' answers in the survey. They create a dynamic and interactive environment that breaks with the monotony of regular lectures.

As work in process mentioned in Section 4, this activity is being extended to solidify the algorithmic methodology of the CWS heuristic. The algorithm can be explained in detail in the second lecture (as it is done now), and then students can apply it to the 20-customer VRP as homework for a third lecture. In this additional class, students' answers can be compared to the CWS solution of the DSS. This will be good practice to better prepare them for the final exam.

Regarding the future, this activity has been used for two academic years and has supposed a quite novel and entertaining experience for the students. As courses go by, this novelty is lost 
and the activity information can be passed from some students to the others. Although the website access can be blocked during the period in which this activity is carried out, students may discover its existence and lose their interest. There is also the risk of them searching directly for the CWS algorithm, and avoiding the entire problem struggle. This issue could be partly remedied by introducing new features like heterogeneous vehicles or more complex cost functions to increase realism. This is a delicate matter though, as there is always the compromise between realism and solvability in PBL. Despite these risks, the pros of using this activity outnumber its cons, something that is supported by the positive student evaluations received.

\section{Acknowledgments}

The authors are thankful to Guillem Gimenez and Jaquelina Ogea for their collaboration in the project, and to Stephen J. Childe and Desirée Knoppen for their invaluable feedback. This work has been partially supported by the Centre for Teaching Quality and Innovation (CQUID) of Universitat Pompeu Fabra, and by the Spanish Ministry of Economy and Competitiveness (TRA2013-48180-C3-2-P).

\section{References}

Ahern, A.A. (2010), “A case study: Problem-based learning for civil engineering students in transportation courses”, European Journal of Engineering Education, Vol. 35 No. 1, pp. 109-116.

Alvarstein, V. and Johannesen, L.K. (2001), "Problem-based learning approach in teaching lower level logistics and transportation”, International Journal of Physical Distribution \& Logistics Management, Vol. 31 No. 7/8, pp. 557-573.

Andrade-Pineda, J.L., Gonzalez-R, P.L. and Framinan, J.M. (2013), “A Decision-Making Tool for a Regional Network of Clinical Laboratories”, Interfaces, Vol. 43 No. 4, pp. 360-372.

Bamford, D., Karjalainen, K. and Jenavs, E. (2012), “An evaluation of problem-based assessment in teaching operations management”, International Journal of Operations \& Production Management, Vol. 32 No. 12, pp. 1493-1514.

Ben-Zvi, T. (2007), “Using Business Games in Teaching DSS”, Journal of Information Systems Education, Vol. 18 No. 1, pp. 113-124.

Brownell, J. and Jameson, D.A. (2004), "Problem-Based Learning in Graduate Management Education: An Integrative Model and Interdisciplinary Application”, Journal of Management Education, Vol. 28 No. 5, pp. 558-577.

Campbell, A., Goentzel, J. and Savelsbergh, M. (2000), "Experiences with the use of supply chain management software in education”, Production and Operations Management, Vol. 9 No. 1, pp. 66-80.

Carravilla, M.A. and Oliveira, J.F. (2004), “Teaching logistics without formal classes: a case study”, European Journal of Engineering Education, Vol. 29 No. 4, pp. 571-580.

Chou, D.C., Tan, X. and Yen, D.C. (2004), “Web technology and supply chain management”, Information Management \& Computer Security, Vol. 12 No. 4, pp. 338-349. 
Chwif, L. and Barretto, M.R.P. (2003), "Simulation models as an aid for the teaching and learning process in operations management” , in Chick, S., Sánchez, P.J., Ferrin, D. and Morrice, D.J. (Eds.), Proceedings of the 2003 Winter Simulation Conference, IEEE Press, New Orleans, LA, 7-10 December, pp. 1994-2000.

Clarke, G. and Wright, J. (1964), "Scheduling of vehicles from a central depot to a number of delivering points”, Operations Research, Vol. 12 , pp. 568-581.

European Comission (2011), “Roadmap to a Single European Transport Area”, available at: http://ec.europa.eu/transport/strategies/facts-and-figures/all-themes/index_en.htm (accessed 23 April 2014).

Faulin, J., Sarobe, P. and Simal, J. (2005), “The DSS LOGDIS optimizes delivery routes for FRILAC’s frozen products”, Interfaces, Vol. 35 No. 3, pp. 202-214.

Gammelgaard, B. and Larson, P.D. (2001), "Logistics skills and competencies for supply chain management”, Journal of Business Logistics, Vol. 22 No. 2, pp. 27-50.

Grasas, A., Ramalhinho, H. and Juan, A.A. (2013), "Operations research and simulation in master's degrees: A case study regarding different universities in Spain”, in Pasupathy, R., Kim, S.-H., Tolk, A., Hill, R. and Kuhl, M.E. (Eds.), Proceedings of the 2013 Winter Simulation Conference, IEEE Press, Washington DC, 9-12 December, pp. 3609-3619.

Gravier, M.J. and Farris, M.T. (2008), “An analysis of logistics pedagogical literature: Past and future trends in curriculum, content, and pedagogy” , The International Journal of Logistics Management, Vol. 19 No. 2, pp. 233-253.

Gudmundsson, S.V. and Nijhuis, J. (2001), “Collaborative learning in logistics and transport: The application of 3WIM”, International Journal of Physical Distribution \& Logistics Management, Vol. 31 No. 7/8, pp. 537-556.

Hmelo-Silver, C.E. (2004), “Problem-Based Learning: What and How Do Students Learn?”, Educational Psychology Review, Vol. 16 No. 3, pp. 235-266.

Van Hoek, R.I. (2001), “Logistics education: Achieving market and research driven skill development”, International Journal of Physical Distribution \& Logistics Management, Vol. 31 No. 7, pp. 505-519.

Hung, I.W., Choi, A.C.K. and Chan, J.S.F. (2003), “An Integrated Problem-Based Learning Model for Engineering Education”, International Journal of Engineering Education, Vol. 19 No. 5, pp. 734-737.

Jacobs, F.R. (2000), “Playing the Beer Distribution Game Over the Internet”, Production and Operations Management, Vol. 9 No. 1, pp. 31-39.

Jahangirian, M., Eldabi, T., Naseer, A., Stergioulas, L.K. and Young, T. (2010), "Simulation in manufacturing and business: A review”, European Journal of Operational Research, Vol. 203 No. 1, pp. 1-13.

Johnson, M.E. and Pyke, D.F. (2000), “A framework for teaching supply chain management”, Production and Operations Management, Vol. 9 No. 1, pp. 2-18. 
Kanet, J.J. and Barut, M. (2003), "Problem-Based Learning for Production and Operations Management”, Decision Sciences Journal of Innovative Education, Vol. 1 No. 1, pp. 99118.

Kanet, J.J. and Stößlein, M. (2008), “Using a Supply Chain Game to Effect Problem-Based Learning in an Undergraduate Operations Management Program”, Decision Sciences Journal of Innovative Education, Vol. 6 No. 2, pp. 287-295.

Lancioni, R., Forman, H. and Smith, M.F. (2001), "Logistics and supply chain education: Roadblocks and challenges" , International Journal of Physical Distribution \& Logistics Management, Vol. 31 No. 10, pp. 733-745.

Laporte, G. (2009), “Fifty Years of Vehicle Routing”, Transportation Science, Vol. 43 No. 4, pp. 408-416.

Léger, P.-M., Cronan, P., Charland, P., Pellerin, R., Babin, G. and Robert, J. (2012), “Authentic OM problem solving in an ERP context”, International Journal of Operations \& Production Management, Vol. 32 No. 12, pp. 1375-1394.

Lewis, M.A. and Maylor, H.R. (2007), “Game playing and operations management education”, International Journal of Production Economics, Vol. 105 No. 1, pp. 134-149.

Mabrouk, P.A. (2007), “Introduction” , in Mabrouk, P.A. (Ed.), Active Learning: Models from the Analytical Sciences, American Chemical Society, Washington DC, pp. 1-13.

McKone, K. and Bozewicz, J. (2003), “The ISM simulation: Teaching integrated management concepts”, Journal of Management Education, Vol. 27 No. 4, pp. 497-515.

Ruiz, R., Maroto, C. and Alcaraz, J. (2004), “A decision support system for a real vehicle routing problem”, European Journal of Operational Research, Vol. 153 No. 3, pp. 593606.

Smith, G.F. (2005), “Problem-Based Learning: Can it Improve Managerial Thinking?”, Journal of Management Education, Vol. 29 No. 2, pp. 357-378.

Sterman, J.D. (1989), "Modeling Managerial Behavior: Misperceptions of Feedback in a Dynamic Decision Making Experiment”, Management Science, Vol. 35 No. 3, pp. 321339.

Sweeney, D., Campbell, J. and Mundy, R. (2010), “Teaching supply chain and logistics management through commercial software", The International Journal of Logistics Management, Vol. 21 No. 2, pp. 293-308.

Thomchick, E. (1997), “The Use of Collaborative Learning in Logistics Classes”, Journal of Business Logistics, Vol. 18 No. 2, pp. 191-205.

Toth, P. and Vigo, D. (2002), “An overview of vehicle routing problems”, in Toth, P. and Vigo, D. (Eds.), The vehicle routing problem, SIAM, Philadelphia, PA, pp. 1-26.

Wood, S.C. (2007), “Online Games to Teach Operations”, INFORMS Transactions on Education, Vol. 8 No. 1, pp. 3-9. 
Wu, Y.C. (2007), “Contemporary logistics education: an international perspective”, International Journal of Physical Distribution \& Logistics Management, Vol. 37 No. 7, pp. 504-528. 